\title{
Characterization of Algerian reservoir sludges for use as active additions in cement: new pozzolans for eco-cement manufacture
}

\author{
O. Rodríguez ${ }^{1 *}$, L. Kacimi ${ }^{2}$, A. López-Delgado ${ }^{1}$, M. Frías ${ }^{3}$, A. Guerrero ${ }^{3}$ \\ ${ }^{1}$ National Centre for Metallurgical Research (CENIM-CSIC) Av. Gregorio del Amo, 8, 28040 \\ Madrid, Spain \\ ${ }^{2}$ Université des Sciences et de la Technologie d'Oran «Mohamed Boudiaf» Oran, Algeria. \\ ${ }^{3}$ Eduardo Torroja Institute (IETcc-CSIC), C/ Serrano Galvache, 4, 28033 Madrid, Spain.
}

\begin{abstract}
This paper analyzes the chemical, physical, morphological, mineralogical and pozzolanic characteristics of several reservoir sludges and assesses their potential for use as $20 \%$ additions in blended cement manufacture. The studied sludges exhibit good pozzolanic properties, especially sample 5 which has high $\mathrm{SiO}_{2}, \mathrm{Al}_{2} \mathrm{O}_{3}$ and $\mathrm{Fe}_{2} \mathrm{O}_{3}$ contents. Blended cements prepared with $20 \%$ sludge additions complied with the European standard on compressive strength of one of the standardized cements, above $32.5 \mathrm{MPa}$ at 28 days of curing; except for sample 5, which showed similar compressive strength values to the reference cement and up to $2 \%$ higher values at long curing times.
\end{abstract}

Keywords: reservoir sludge, supplementary cementing materials, pozzolan, blended cement, ecocement

\section{Introduction}

One of the main challenges for the cement industry is to reduce $\mathrm{CO}_{2}$ emissions into the atmosphere during the manufacture of Portland cement $\left(0.89 \mathrm{t} \mathrm{CO}_{2} / \mathrm{t}\right.$ clinker $)$. Efforts in this respect have been ongoing for a number of years due to commitments under the Kyoto Protocol to cut greenhouse gas emissions, in particular $\mathrm{CO}_{2}$. In this context, the use of supplementary cementing materials (natural and waste) is currently a priority research line [1-3]. Mineral additions are commonly employed in the cement industry [4-6] and their use has increased in recent decades thanks to their scientific, technical, environmental and thermal benefits [7-14]. The use of supplementary materials like pozzolans in concrete helps to reduce clinker production (and hence $\mathrm{CO}_{2}$ emissions), avoids landfill

*Corresponding author: e-mail: olgarodriguez@ cenim.csic.es, Phone: +34 915538900, Fax: +34

915347425. 
disposal needs, and can improve the performance of new building materials and thus prolong the service life of buildings; all of which contributes to sustainable development [15].

Reservoir silting is a real environmental problem in Algeria, especially in the west of the country, and is largely due to the dryness of this region and the irregularity of rainfall over the year. Flash floods pick up minerals and sediments from normally dry river beds and carry them downstream to reservoir basins where they are deposited to form the sludges studied in this work. The mineralogical composition of these sludges depends on the regional lithology, and their partial dissolution leads to their chemical reactivation. Silting can severely affect a reservoir's storage capacity, so the sediments need to be periodically removed. This, however, gives rise to fresh environmental problems when sludge is dumped on surrounding land. As an alternative means of disposal it is proposed to use these alumina-silica-rich sludges in replacement of the pozzolans traditionally employed in commercial Portland cement production (fly ash, silica fume, metakaolin and natural pozzolans).

The viability of using this kind of materials in the cement industry has not previously been addressed in the literature, and the present paper offers their first complete characterization from scientific and pozzolanic viewpoints, assessing their behaviour in cement matrixes and analyzing the technical aspects set out in European standards (rheology, setting time and strength). It presents the initial results of a broad project to assess the scientific and technical potential for the use of these sludges as active cement additions.

\section{Materials and methods}

\subsection{Characterization}

The studied sludges come from five reservoirs in several regions of western Algeria: Tiaret (SLD1), El Bayadh (SLD2), Oran (SLD3), Ain Defla (SLD4) and Tipaza (SLD5). Samples SLD1, SLD3 and SLD4 are found in clayey areas and are alumina-silica-rich. Sample SLD2 comes from an area containing Saharan sand and is silica-rich. Sample SLD5 is found in an andesite-rich area and is of an andesitic nature. Sludges were collected at 9 sites in each reservoir basin, dried, premixed, and successively quartered to obtain representative samples. Each sample was crushed and sieved to 80 microns prior to analysis. 
The lime used in the pozzolanic activity test was analytical grade calcium hydroxide (95\% minimum purity, $4.8 \%$ maximum magnesium and alkaline salt contents, and $0.5 \%$ maximum insoluble content).

The cement employed for the technical tests was an ordinary Portland cement (OPC) type CEM I $42.5 \mathrm{~N}$ according to UNE-EN 197-1 standard.

The chemical composition of the sludges was determined by X-ray fluorescence (XRF) using a Philips PW-1480 dispersive energy spectrophotometer, Sc/Mo anode, in working conditions of 80 $\mathrm{kV}$ and $35 \mathrm{~mA}$.

The particle size distribution of the initial sludges (SLD) was determined with a SYPATEC HELOS 12LA laser granulometer [16, 17].

Nitrogen adsorption and desorption measurements were performed on a ASAP 2010, Micromeritics Instrument Corp., using $\mathrm{N}_{2}-77^{\circ} \mathrm{K}$ gas. The samples were outgassed in a vacuum at $50^{\circ} \mathrm{C}$ for $12 \mathrm{~h}$ prior to measurement. Surface areas were calculated from the sorption isotherm data, using the BET (Brunauer-Emmett-Teller) method [18], in the relative pressure range of 0.003-0.3.

The mineral composition of the samples was determined by random powder X-ray diffraction (XRD) on a Bruker D8 advance diffractometer equipped with a $\mathrm{Cu}_{\mathrm{K} \alpha}$ tube. A current of $30 \mathrm{~mA}$ and a voltage of $40 \mathrm{KV}$ were employed as the tube setting. XRD data was collected over a $2 \theta$ range of $5-70^{\circ}$. To check the phyllosilicates in sample SLD5, the oriented and solvated aggregate method with ethylene glycol was used.

\subsection{Pozzolanic test}

The pozzolanic activity of the sludge was studied using an accelerated method. The test consisted of placing the samples in contact with a saturated lime solution at $40^{\circ} \mathrm{C}$ for $1,7,28$ and 90 days. At the end of each period the $\mathrm{CaO}$ concentration in the solution was analyzed. The combined lime $(\mathrm{mmol} / \mathrm{l})$ was obtained by the difference between the concentration in the control saturated lime solution and the $\mathrm{CaO}$ found in the solution in contact with the sample. Commercial metakaolin (MK), fly ash (FA) and silica fume (SF) samples were also used as reference materials in order to establish a comparison [19]. 


\subsection{Blended cements}

The methodology and study of the properties of blended cements were developed in accordance with European standard UNE-EN 197-1 [20]. The blends were prepared using type CEM I 42.5N Portland cement with $20 \%$ (weight) sludge replacements. The mechanical strength of the blended cements was analyzed up to 90 days of curing, preparing cement mortars with a water/binder ratio of 0.5 (this ratio was kept constant throughout to ensure the comparability of results). Prismatic specimens of $4 \times 4 \times 16 \mathrm{~cm}$ were moulded in accordance with the European standard [21]. The setting times and normal consistency were evaluated as per UNE-EN 196-3 (Vicat apparatus) [22].

\section{Results and Discussion}

\subsection{Characterization of sludges}

Table 1 shows the chemical composition (XRF) of the Algerian sludges, which have $\mathrm{SiO}_{2}(33.6 \%-$ $56.8 \%), \mathrm{Al}_{2} \mathrm{O}_{3}(11.4 \%-16.5 \%), \mathrm{CaO}(3.4 \%-27.8 \%), \mathrm{Fe}_{2} \mathrm{O}_{3}(4.6 \%-12.2 \%)$ and $\mathrm{MgO}(1.2 \%-7.9 \%)$ as their major components. Attention is drawn to the $\mathrm{CO}_{2}$ content in samples SLD2-SLD4 which is due to the presence of calcite (see XRD results).

Table 1. Chemical composition of the different sludges determined by XRF (* determined by combustion)

\begin{tabular}{|c|c|c|c|c|c|}
\hline Oxide (\% wt) & SLD1 & SLD2 & SLD3 & SLD4 & SLD5 \\
\hline $\mathrm{SiO}_{2}$ & $49.4 \pm 0.3$ & $40.7 \pm 0.2$ & $41.3 \pm 0.3$ & $33.6 \pm 0.2$ & $56.8 \pm 0.3$ \\
\hline $\mathrm{Al}_{2} \mathrm{O}_{3}$ & $16.5 \pm 0.2$ & $14.5 \pm 0.2$ & $14.6 \pm 0.2$ & $11.4 \pm 0.2$ & $16.5 \pm 0.2$ \\
\hline $\mathrm{CaO}$ & $16.8 \pm 0.2$ & $17.5 \pm 0.2$ & $16.8 \pm 0.2$ & $27.8 \pm 0.2$ & $3.40 \pm 0.09$ \\
\hline $\mathrm{Fe}_{2} \mathrm{O}_{3}$ & $6.3 \pm 0.1$ & $5.2 \pm 0.1$ & $5.1 \pm 0.1$ & $4.6 \pm 0.1$ & $12.2 \pm 0.2$ \\
\hline $\mathrm{MgO}$ & $3.98 \pm 0.09$ & $3.58 \pm 0.09$ & $2.97 \pm 0.08$ & $1.23 \pm 0.05$ & $7.9 \pm 0.1$ \\
\hline $\mathrm{K}_{2} \mathrm{O}$ & $2.51 \pm 0.07$ & $2.75 \pm 0.08$ & $1.90 \pm 0.06$ & $1.09 \pm 0.05$ & $0.89 \pm 0.04$ \\
\hline $\mathrm{SO}_{3}$ & $1.10 \pm 0.05$ & $0.25 \pm 0.02$ & $0.21 \pm 0.02$ & $0.047 \pm 0.004$ & $0.079 \pm 0.006$ \\
\hline $\mathrm{TiO}_{2}$ & $0.71 \pm 0.04$ & $0.61 \pm 0.03$ & $0.58 \pm 0.03$ & $0.56 \pm 0.03$ & $0.63 \pm 0.03$ \\
\hline $\mathrm{Na}_{2} \mathrm{O}$ & $0.67 \pm 0.03$ & $0.16 \pm 0.01$ & $0.31 \pm 0.02$ & $0.30 \pm 0.02$ & $0.42 \pm 0.02$ \\
\hline $\mathrm{P}_{2} \mathrm{O}_{5}$ & $0.54 \pm 0.04$ & $0.27 \pm 0.02$ & $0.45 \pm 0.04$ & $0.088 \pm 0.008$ & $0.096 \pm 0.008$ \\
\hline $\mathrm{Cl}_{-}$ & $0.021 \pm 0.002$ & $0.022 \pm 0.002$ & $0.019 \pm 0.002$ & - & $0.011 \pm 0.002$ \\
\hline $\mathrm{CO}_{2} *$ & $0.58 \pm 0.01$ & $14.42 \pm 0.02$ & $15.81 \pm 0.06$ & $19.1 \pm 0.06$ & $0.62 \pm 0.04$ \\
\hline
\end{tabular}


Sludge SLD5 has a majority $\mathrm{SiO}_{2}$ content and high $\mathrm{Fe}_{2} \mathrm{O}_{3}(>10 \%)$ and $\mathrm{MgO}(\sim 8 \%)$ contents, but its $\mathrm{CaO}$ content is lower than that observed in the other sludges, mainly due to its lack of calcite. The other sludges (SLD1-SLD4) have quite similar chemical compositions, although their behaviour is different, as can be seen in the rest of techniques employed. The high calcium oxide content in SLD1 is due to the presence of different calcium-containing mineralogical compounds, and not to the presence of calcite like in SLD2-SLD4 (Fig. 3).

Silica, alumina and iron oxide are all potentially reactive oxides in terms of pozzolanic activity (Taylor, 1997). The sludges with the highest contents of these oxides are SLD5 (more than 85\%) and SLD1 (about 72\%), which suggests that these two materials may be the most active on the basis of their chemical characteristics.

Particle size distribution, as determined by laser diffraction, is shown in Fig. 1. SLD1, SLD2 and SLD4 are all trimodal, as shown by the distribution density curves, with peaks around 3.1, 15 and $36 \mu \mathrm{m}$ for SLD 1; 6, 18 and $36 \mu \mathrm{m}$ for SLD 2; and 6, 15 and $51 \mu \mathrm{m}$ for SLD4. SLD3 shows a bimodal distribution with maxima at 3.7 and $15 \mu \mathrm{m}$ while SLD5 only shows a broad maximum around $61 \mu \mathrm{m}$.

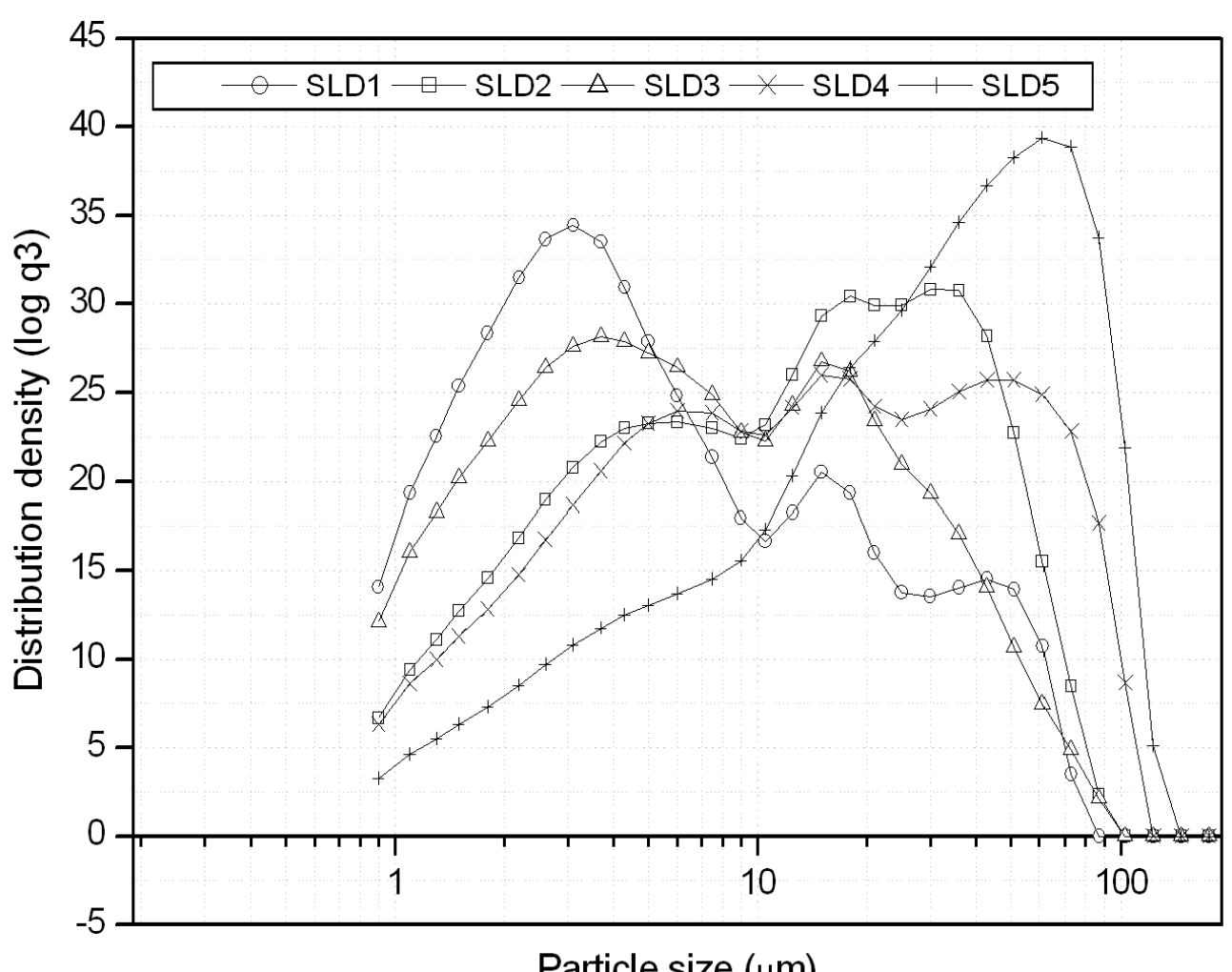

Fig. 1. Particle size distribution of sludges 
Fig. 2 shows the specific surface area (BET) of the analyzed sludge samples. SLD5 has the largest specific surface area, followed by SLD2, SLD4 and SLD3. These values are very high compared to silica fume $\left(15 \mathrm{~m}^{2} / \mathrm{g}\right)$. SLD1 has a very low BET area, which is closer to the value of cement $(<1$ $\left.\mathrm{m}^{2} / \mathrm{g}\right)[4]$.

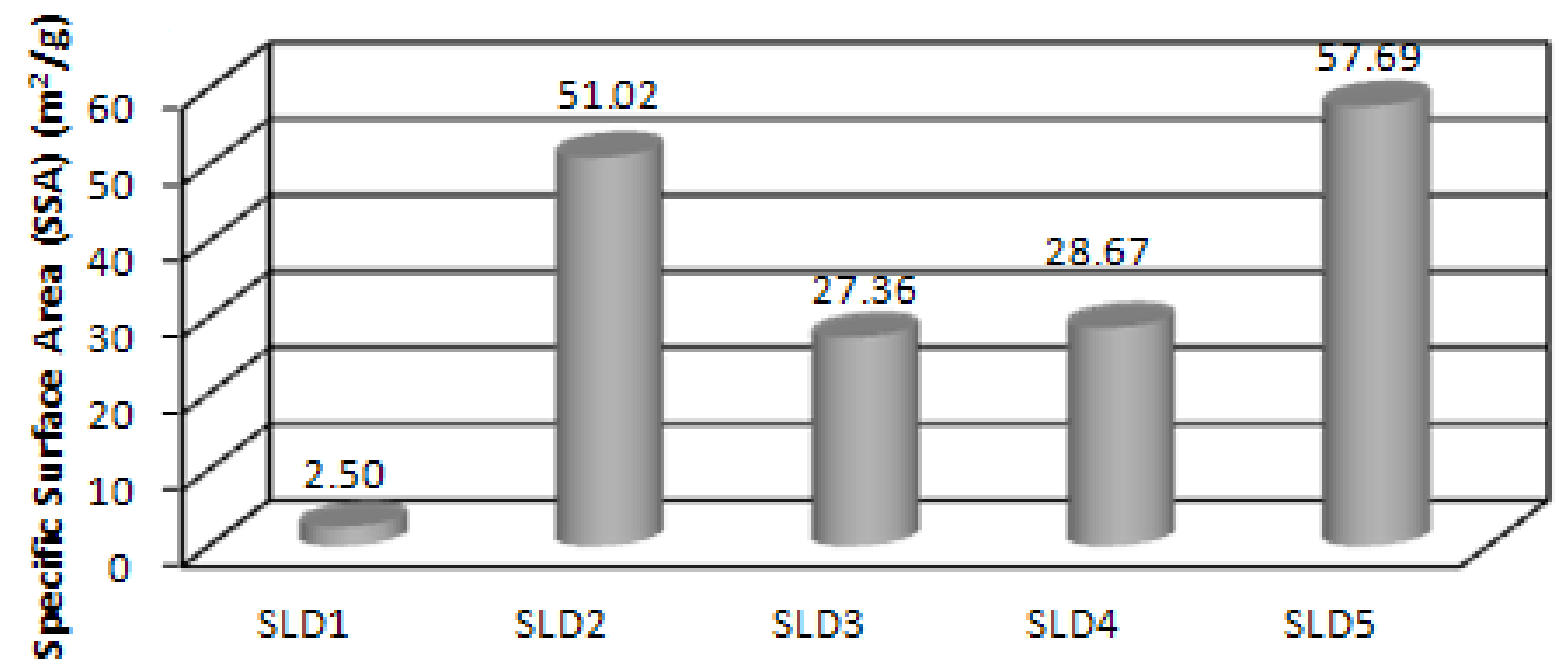

Fig. 2. Specific surface area of reservoir sludges determined by BET.

These results may suggest a certain independence between the BET specific surface area and the particle size distribution determined by laser diffraction. This is because the BET specific surface area is strongly influence by the internal porous structure of the particles. For this reason, when studying the potential reactivity of wastes or other particles it is important to take into account not only the particle size distribution but also the internal porous structure of the material.

The study of XRD patterns for the initial samples shows that SLD2, SLD3 and SLD4 are quite similar, but the patterns for SLD1 and SLD5 are very different. It is interesting to note the presence of silicon oxide (as quartz (1) JCPDS files 89-8937 (SLD1-4) and 46-1042 (SLD5), which is due to the source of the samples. The other minerals detected are mainly silicates (akermanite (5, JCPDS file 35-592), rankinite (9, JCPDS file 22-539)) and/or silicoaluminates (diopside (7, JCPDS file 411370), gehlenite (4, JCPDS file 79-1726)). The pattern for SLD5 shows a low degree of crystallinity, unlike the other sludges, indicating a higher reactivity due to the presence of amorphous silica and alumina, more reactive phases. In this case, due to the suspected presence of clay minerals, both the oriented and solvated aggregate method and the random powder method were used. The oriented and solvated aggregate method has identified the presence of smectite, while the random powder method has detected the reflection corresponding to muscovite (JCPDS file 80-742), opal (JCPDS file 38-448) and albite (JCPDS file 9-466). The presence of calcite (JCPDS file 86-2340) is detected in the patterns for SLD2, SLD3 and SLD4, fitting in XRF data, 
where the $\mathrm{CO}_{2}$ content of these sludges is between 14 and 19\%. The XRD pattern for SLD1 also shows differences compared to the other samples; the iron content observed in XRF is reflected in XRD as $\mathrm{Fe}_{2} \mathrm{O}_{3}$ (JCPDS file 16-653) instead of magnetite (JCPDS file 76-958), as in sludges SLD24 , and calcite is not detected.

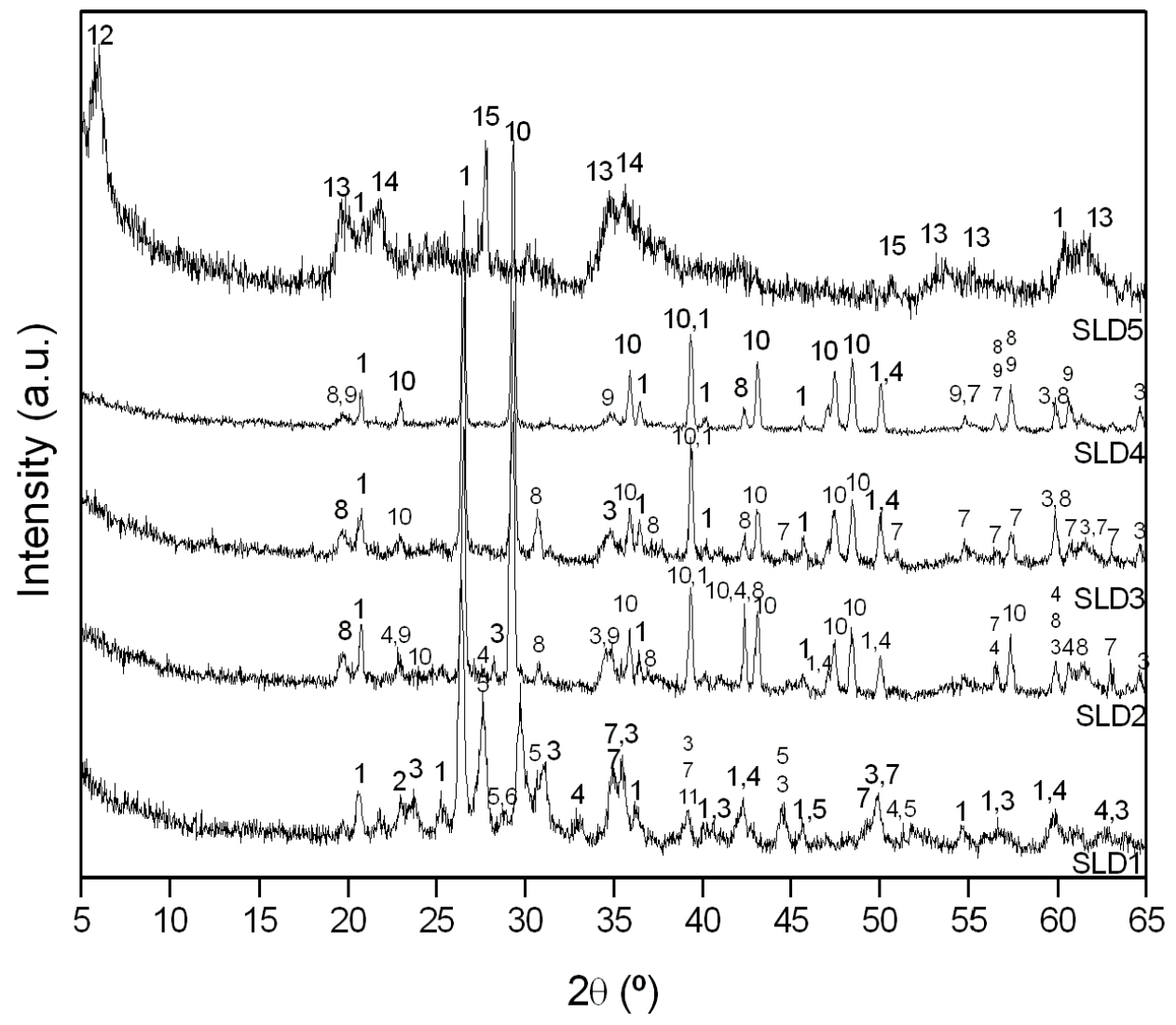

Fig. 3. Diffractograms for reservoir sludges (1: Quartz; 2: $\mathrm{Ca}_{0.5} \mathrm{Si}_{3} \mathrm{Al}_{3} \mathrm{O}_{11} ; 3: \mathrm{Ca}_{5}\left(\mathrm{SiO}_{4}\right)_{2}(\mathrm{OH})_{2} ; 4$ :

Gehlenite; 5: Akermanite; 6: $\mathrm{Ca}_{1.82} \mathrm{Si}_{0.36} \mathrm{Al}_{3.64} \mathrm{O}_{8}$; 7: Diopside; 8: Magnetite; 9: Rankinite; 10:

Calcite; 11: $\mathrm{Fe}_{2} \mathrm{O}_{3}$; 12: Smectite; 13: Muscovite; 14: Opal; 15: Albite)

\subsection{Pozzolanic activity of the analyzed sludges}

The results obtained for the sludges combined with lime are shown in Fig. 4. The samples are compared with normalized pozzolans such as silica fume (SF), fly ash (FA) and metakaolin (MK) and all show high pozzolanic activity in terms of fixed lime results.

Pozzolanic activity is lower for the Algerian sludges than for SF at short reaction times (1-7 days) and higher than FA at all ages. It is important to note that the pozzolanic activity of SLD5 is higher (60\% of fixed lime) than that of MK (30\%), which is considered a high reactivity pozzolan [23, 24]. At 28 days of reaction, all the sludges have consumed between 60 and $80 \%$ of the available lime, and after 90 days the fixed lime content is only slightly higher. The recorded values are close to 
those of FA and MK, except for SLD5. With this activity data it may be stated that the most active sludge is SLD5, followed by SLD1 and finally by SLD2-4.

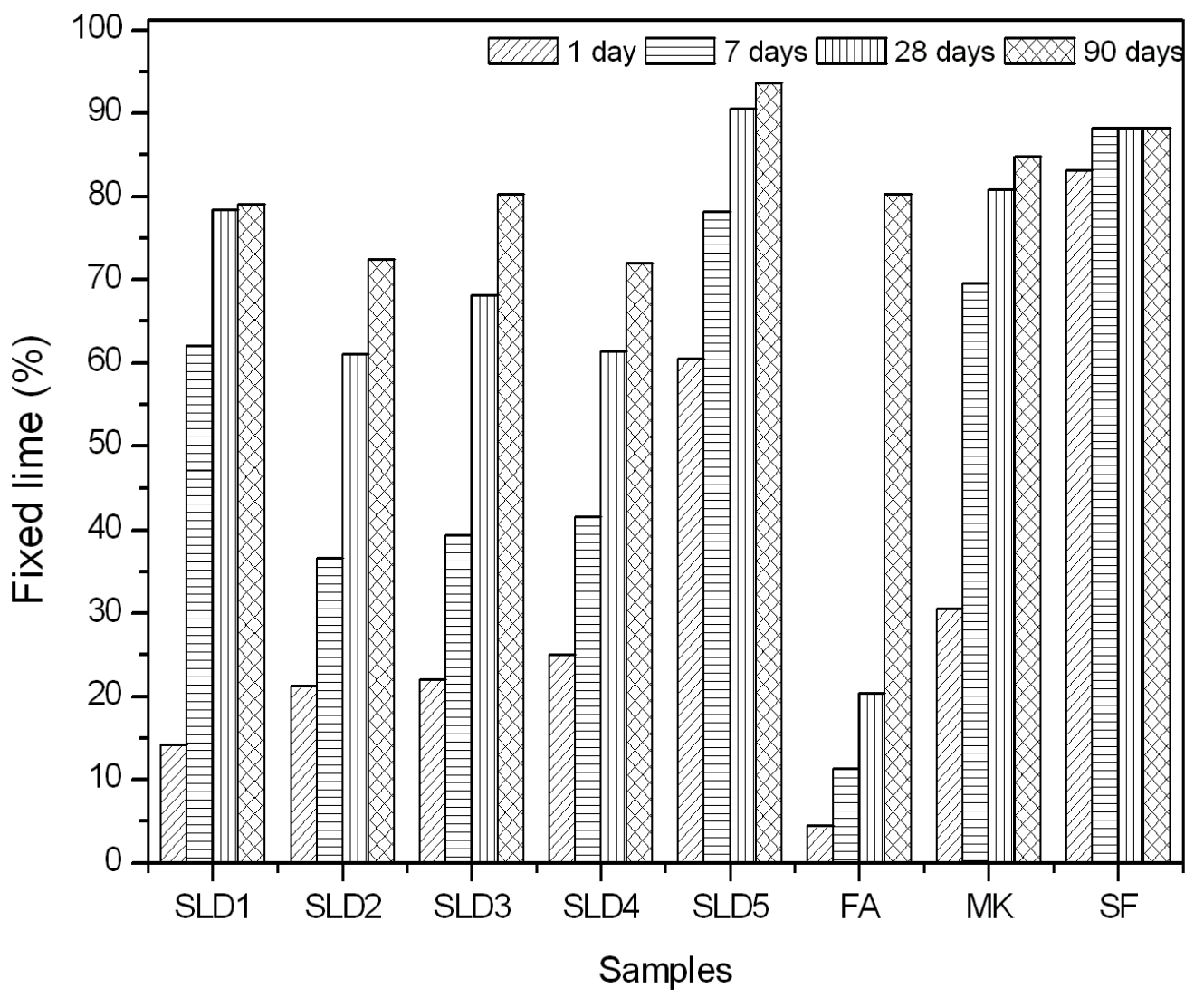

Fig. 4. Pozzolanic activity of reservoir sludges (SLD1-SLD5), FA, MK and SF

In the absence of further studies, this pozzolanic sequence may be related on the one hand to the acid components content (silica and alumina) in the initial samples, mainly in SLD5 (Table 1), and on the other hand to the difference in the BET values found for each sludge; properties that play an important role in reactivity. With regard to the latter consideration, the BET value of SLD1 (2.50 $\mathrm{m}^{2} / \mathrm{g}$ ) does not justify its high activity compared to the other samples (SLD2-SLD4). The lower activity found in SLD2-SLD4 (compared to SLD1 and SLD5) may be related to the presence of calcite (Table 3 and Figure 3), which has a negative influence on the pozzolanic reaction, mainly at short times ( $<7$ days).

Although sludges SLD2, SLD3 and SLD4 have a large BET specific surface area, especially SLD2, they do not present great reactivity at early ages ( 1 to 7 days) due to their high calcium carbonate content (Fig. 3). This causes the filler effect to predominate over the pozzolanic reaction. Sludge SLD1, which has a high quartz content, presents the smallest BET specific surface area and the lowest reactivity at early ages ( 1 to 7 days) but not at 28 days, when the amount of fixed lime is 
around $80 \%$ and close to the value of MK. For its part, the high reactivity of SLD5 is due to its lower crystallinity (Fig. 3) and more porous internal structure than the other sludges.

\subsection{Blended cements}

Table 2 compares the physical properties of the blended cements prepared with $20 \%$ sludges (weight replacement) and the reference OPC.

Table 2. Physical properties of blended cements

\begin{tabular}{cccc}
\hline & $\begin{array}{c}\text { Consistency } \\
(\text { wt } \%)\end{array}$ & $\begin{array}{c}\text { Initial setting } \\
\text { time (min)* }\end{array}$ & $\begin{array}{c}\text { Final setting } \\
\text { time (min)* }\end{array}$ \\
\hline OPC & 27.7 & 180 & 255 \\
OPC+20\% SLD1 & 27.8 & 181 & 246 \\
OPC+20\% SLD2 & 29.4 & 182 & 274 \\
OPC+20\% SLD3 & 30.0 & 185 & 267 \\
OPC+20\% SLD4 & 26.3 & 190 & 280 \\
OPC+20\% SLD5 & 28.0 & 205 & 290 \\
Standard UNE-EN 197-1 & - & $\geq 60$ & - \\
\hline
\end{tabular}

The incorporation of the sludges slightly modifies the consistency of the blended cements. Similar values are found for the cases of SLD1 and SLD5, and higher values for SLD2 and SLD3, while the addition of SLD4 leads to a decrease in consistency (about 5\%) compared to the control paste. This behaviour must be related with the higher calcium carbonate content in SLD4, which is well known to act as a "filler" during the first hours of reaction and because of its softness becomes considerably finer than cement [4], requiring more normal consistency water. This behaviour has also previously been observed in activated paper sludges with supplementary cementing material formed by metakaolinite and calcite [25-27].

The addition of this kind of pozzolans to the cement matrix does not affect setting time values, mainly the initial setting time, because it is a standardized method. In this case, the variations observed are within the test error margin. From the results obtained, all the blended cements are seen to comply with the standard requirements (initial setting time $\geq 60 \mathrm{~min}$ ) for all strength classes. 
Compressive strength is also affected by the incorporation of supplementary materials, mostly diminishing compared to the reference mortar (Table 3). At early ages the substitution effect (filler effect of additions) predominates over the pozzolanic effect, while from 28 days the strength losses are seen to recover due to the pozzolanic properties of the sludges. A slightly (2\%) higher compressive strength value than the reference mortar is only achieved after 90 days of reaction with the $20 \%$ SLD5 addition. Taking into account the mechanical requirements of the European standard at 28 days of curing [20], only the mortars prepared with SLD3 and SLD5 comply with the minimum standard strength value for strength class $42.5 \mathrm{R}$ and $\mathrm{N}(\geq 42.5 \mathrm{MPa})$. The other sludges (SLD1, SLD2 and SLD4) show values slightly below the standard value, but are viable for the preparation of 32.5 strength class cements.

Table 3. Compressive strength of blended cements

\begin{tabular}{ccccc}
\hline Compressive strength $(\mathrm{MPa})$ & 2 days & 7 days & 28 days & 90 days \\
\hline OPC & $23.3 \pm 1.2$ & $38.8 \pm 1.9$ & $50.8 \pm 2.5$ & $60.3 \pm 3.0$ \\
OPC+20\% SLD1 & $18.3 \pm 0.9$ & $29.7 \pm 1.5$ & $40.9 \pm 2.1$ & $45.7 \pm 2.3$ \\
OPC+20\% SLD2 & $12.4 \pm 0.6$ & $30.3 \pm 1.5$ & $38.6 \pm 1.9$ & $51.9 \pm 2.6$ \\
OPC+20\% SLD3 & $14.2 \pm 0.7$ & $28.4 \pm 1.4$ & $42.7 \pm 2.1$ & $55.8 \pm 2.8$ \\
OPC+20\% SLD4 & $13.9 \pm 0.7$ & $29.6 \pm 1.5$ & $41.0 \pm 2.1$ & $52.6 \pm 2.6$ \\
OPC+20\% SLD5 & $15.9 \pm 0.8$ & $31.7 \pm 1.6$ & $47.9 \pm 2.4$ & $61.4 \pm 3.1$ \\
Requirements UNE-EN 197-1 & $\geq 10$ & - & $\geq 32.5,42.5$ & - \\
\hline
\end{tabular}

It is important to note that strength development between 2 and 7 days is higher in the case of the blended cements than for the reference OPC (66\%), and reaches $114 \%$ for the SLD4 addition. With regard to the improvement between 7 and 28 days, this reaches 34\% for the SLD2 addition, above the OPC value (18\%), which suggests that this kind of supplementary material achieves long term strength development.

\section{Conclusions}

The five studied Algerian reservoir sludges are mainly composed of $\mathrm{SiO}_{2}, \mathrm{Al}_{2} \mathrm{O}_{3}, \mathrm{Fe}_{2} \mathrm{O}_{3}$ and $\mathrm{CaO}$, and three of them (samples SLD2-SLD4) have a high $\mathrm{CO}_{2}$ content. The mineralogical composition of the sludges is complex, with quartz as the major crystalline phase, except in the case of SLD5, where the presence of phyllosilicates (smectite and muscovite) leads to a very low crystallinity value. All the sludges present a very high BET specific surface area and high pozzolanic activity. 
SLD5 is the most active sample and shows similar behaviour to silica fume, one of the most active pozzolans used in the cement industry.

The blended cements prepared with $20 \%$ of each sludge show higher consistency values than OPC (except SLD4) due to the increased water demand of the pozzolans. The setting time is also higher due to the typical dilution effects of pozzolanic additions. With regard to compressive strength, the blended cements show lower values than OPC, except for SLD5, whose compressive strength is not only similar to that of the reference OPC at 28 days of reaction but even higher after long curing times (90 days).

Considering all of the above, it may be concluded that these sludges can be used as active additions to prepare blended cements with suitable properties. However, it is necessary to obtain a deeper knowledge of their behaviour and to test the durability of the resulting blended cements in order to ensure the good behaviour of the sludges in future cementing matrixes.

\section{Acknowledgements}

The authors are grateful to the Spanish Agency for International Development Cooperation (AECID) for its financial support (Project number A1/038832/11). Dr. O. Rodriguez would also like to thank CSIC (Spain) for the grant JAEDoc_09_00121 (FSE 2007-2013 programme).

\section{References}

[1] Taylor HFW, Mohan K, Moir GK. Analytical study of pure and extended portland-cement pastes .2. Fly ash-cement and slag-cement pastes. Journal of the American Ceramic Society. 1985;68(12):685-90.

[2] Lilkov V, Stoitchkov V. Effect of the "Pozzolit" active mineral admixture on the properties of cement mortars and concretes .2. Pozzolanic activity. Cement and Concrete Research. 1996;26(7):1073-81.

[3] Çavdar A, Yetgin Ş. Availability of tuffs from northeast of Turkey as natural pozzolan on cement, some chemical and mechanical relationships. Construction and Building Materials. 2007;21(12):2066-71.

[4] Taylor HFW. Cement Chemistry 1997.

[5] Mehta K. Role of pozzolanic and cementitious material in sustainable development of the concrete industry. In: Institute AC, editor. Sixth CANMET/ACI International Conference on Durability of Concrete. Chennai (India): American Concrete Institute; 1998. p. 1-20.

[6] Nili M, Salehi AM. Assessing the effectiveness of pozzolans in massive high-strength concrete. Construction and Building Materials. 2010;24(11):2108-16.

[7] Siddique R. Waste Materials and By-Products in Concrete. Berlin: Springer; 2008.

[8] Pera JA, J. Chabannet, M. Ambroise, J., Chabannet, M., (2001), Transformation of Wastes into Complementary CementingMaterials;. In: Malhotra VM, editor. 7th International Conference on Fly Ash, Silica Fume, Slag and Natural Pozzolans in Concrete. Chenai (India): American Concrete Institute; 2001. p. 459-75. 
[9] De Rojas MIS, Marin FP, Frias M, Rivera J. Properties and performances of concrete tiles containing waste fired clay materials. Journal of the American Ceramic Society. 2007;90(11):355965 .

[10] Frias M, de Rojas MIS, Santamaria J, Rodriguez C. Recycling of silicomanganese slag as pozzolanic material in Portland cements: Basic and engineering properties. Cement and Concrete Research. 2006;36(3):487-91.

[11] Stark J. Recent advances in the field of cement hydration and microstructure analysis. Cement and Concrete Research. 2011;41(7):666-78.

[12] Singh NB, Singh VD, Rai S. Hydration of bagasse ash-blended portland cement. Cement and Concrete Research. 2000;30(9):1485-8.

[13] Pacewska B, Blonkowski G, Wilinska I. Investigations of the influence of different fly ashes on cement hydration. Journal of Thermal Analysis and Calorimetry. 2006;86(1):179-86.

[14] Sata V, Jaturapitakkul C, Kiattikomol K. Influence of pozzolan from various by-product materials on mechanical properties of high-strength concrete. Construction and Building Materials. 2007;21(7):1589-98.

[15] Anil DU, Hulusi OM, Ozgur E. Utilization of waste materials in concrete production for sustainable development. Environmental Engineering and Management Journal. 2009;8(4):695-9.

[16] Frias M, Derojas MIS, Luxan MP, Garcia N. Determination of specific surface-area by the laser diffraction technique - comparison with the blaine permeability method. Cement and Concrete Research. 1991;21(5):709-17.

[17] Frias M, deRojas MIS. Microstructural alterations in fly ash mortars: Study on phenomena affecting particle and pore size. Cement and Concrete Research. 1997;27(4):619-28.

[18] Brunauer S, Emmett PH, Teller E. Adsorption of gases in multimolecular layers. Journal of the American Chemical Society. 1938;60:309-19.

[19] Frias M, Rodriguez O, Vegas I, Vigil R. Properties of calcined clay waste and its influence on blended cement behavior. Journal of the American Ceramic Society. 2008;91(4):1226-30.

[20] European Standard UNE EN 197-1:2000/A1:2005. Composition, specifications and conformity for common cements. 2005.

[21] European Standard UNE EN 196-1:2005. Methods of testing cement - Part 1: Determination of strength. 2005.

[22] European Standard UNE EN 196-3:2005. Methods of testing cement - Part 3: Determination of setting times and soundness. 2005.

[23] Frias M. The effect of metakaolin on the reaction products and microporosity in blended cement pastes submitted to long hydration time and high curing temperature. Advances in Cement Research. 2006;18(1):1-6.

[24] Frias M. Study of hydrated phases present in a MK-lime system cured at 60 degrees C and 60 months of reaction. Cement and Concrete Research. 2006;36(5):827-31.

[25] Segui P, Aubert JE, Husson B, Measson M. Characterization of wastepaper sludge ash for its valorization as a component of hydraulic binders. Applied Clay Science. 2012;57:79-85.

[26] Frias M, Vigil R, Garcia R, Rodriguez O, Goni S, Vegas I. Evolution of mineralogical phases produced during the pozzolanic reaction of different metakaolinite by-products: Influence of the activation process. Applied Clay Science. 2012;56:48-52.

[27] Vigil de la Villa R, Frias M, Sánchez de Rojas MI, Vegas I, Garcia R. Mineralogical and morphological changes of calcined paper sludge at different temperatures and retention in furnace. Applied Clay Science. 2007;36(4):279-86. 